\title{
Industrial Model Validation of a WWT Bubbling Fluidized Bed Incinerator
}

\author{
Souad Rabah ${ }^{1,2,3,4}$ Rodrigo O. Brochado ${ }^{2,4}$ Hervé Coppier ${ }^{1,2}$ Mohammed Chadli ${ }^{1,2}$ Nesrine \\ Zoghlami $^{4}$ Mohamed Saber Naceur ${ }^{4}$ Sam Azimi $^{5}$ Vincent Rocher ${ }^{5}$ \\ ${ }^{1}$ MIS Laboratory, 80000 Amiens, France. \\ ${ }^{2}$ ESIEE-Amiens, 80082 Amiens, France. \{COPPIER, RABAH_S\} @esiee-amiens.fr \\ ${ }^{3}$ University of Picardie Jules Verne,(UPJV) 80039 Amiens, France. mohammed.chadli@u-picardie.fr \\ ${ }^{4}$ LTSIRS Laboratory, ENIT,Tunis El Manar University, 1002 Tunis,Tunisia \\ ${ }^{5}$ Direction of Developement and Prospective, SIAAP, 92700 Colombes, France.
}

\begin{abstract}
The environmental concern has significantly raised and specially in the case of bioprocess industries where new standards are more and more strict. In this context, areas of new research have been developed to enhance biological treatment processes productivity and reduce emission of toxic substance. To ensure the control of the incineration variables, a describing model should be determined. In our previous work, we presented multi variable identification results relative- to SIAAP incineration process. This paper concerns model validation of a fluidized-bed incineration furnace by different quality criteria. In this case, our focus is on production phase defined by two incineration modes. Thus, the observed data of each model is compared with the predicted data using quality criteria.
\end{abstract}

Keywords: validation methods, fluidized-bed furnace, subspace state-space system N4SID

\section{Introduction}

Knowing well a dynamic system is a good way to develop its robust efficient control. It is useful for precise weather forecast, general data predictions, model-based simulation and others. For this reason, modelling process and its validation need great attention. Over the past years, new identification methods have been developed to achieve better results in some specific systems, as it can be seen in (Grossmann et al., 2009). Other traditional methods are also developed and adopted, as the N4SID algorithm (Van Overschee and De Moor, 2012; Rabah et al., 2016), that still has satisfactory results in system identifications (Grossmann et al., 2009; Panday et al., 2009; Kojio et al., 2014). An identification process results in a dynamic model which is believed to be the best approximation of certain real process.

However, even using tested and approved methods, a system identification may not give what is expected from its model. It can diverge in peak values, up or down trends, model time constant and more.In consequence, one or more validation methods must be applied on the identified model to analyses its fit with the real process.
In this paper, model validation of a fluidized-bed incineration furnace by six quality criteria is performed. The furnace is owned by SIAAP (Rabah et al., 2016; Mailler et al., 2014) that provides raw measured data to be processed. The measured temperature of each part of the furnace as well as other signals useful for modelling are provided in a thirty-second sample time. Prediction data of resultant model are then compared to observed data for each incinerator sub model. The validation methods adopted are known as NRMSE, LCE and NMSE, AME, MSE and MSDE defined in (Hauduc, 2011). Finally, the results are analyzed and compared to each other. Validation methods are also used for on-line identification methods.

This paper is organized as follows: in the next section SIAAP is presented. The identification method and its results are presented in Section 3. The validation methods adopted for this paper are defined in Section 4. The validation results for each model are presented in section 5 .

\section{Industrial Process Description}

\subsection{SIAAP Waste water and sewage Sludge Treatment Process}

The SIAAP is a French public institution. It was founded in 1971 by the Council of Paris in order to perform the wastewater treatment (WWT) of Greater Paris due to the poor quality of the city's rivers at that time. Nowadays, SIAAP performs the transport, storage, management and purification of wastewater of 180 communes reaching almost nine million users. It can purify more than 2,5 million $m^{3}$ (Mailler et al., 2014) of wastewater each day with its 6 treatment stations.

In Seine Centre Plant, where the studied sludge incinerator furnace is located, WWT flux can get up to $2,8 \mathrm{~m}^{3}$ per second in dry weather. That infrastructure allows to change treatment process and can purify up to $12 \mathrm{~m}^{3}$ of wastewater per second. In this site, there are two different ways of treatment performed: wastewater treatment and sludge treatment.

The WWT in Seine Center Plant is divided in three 


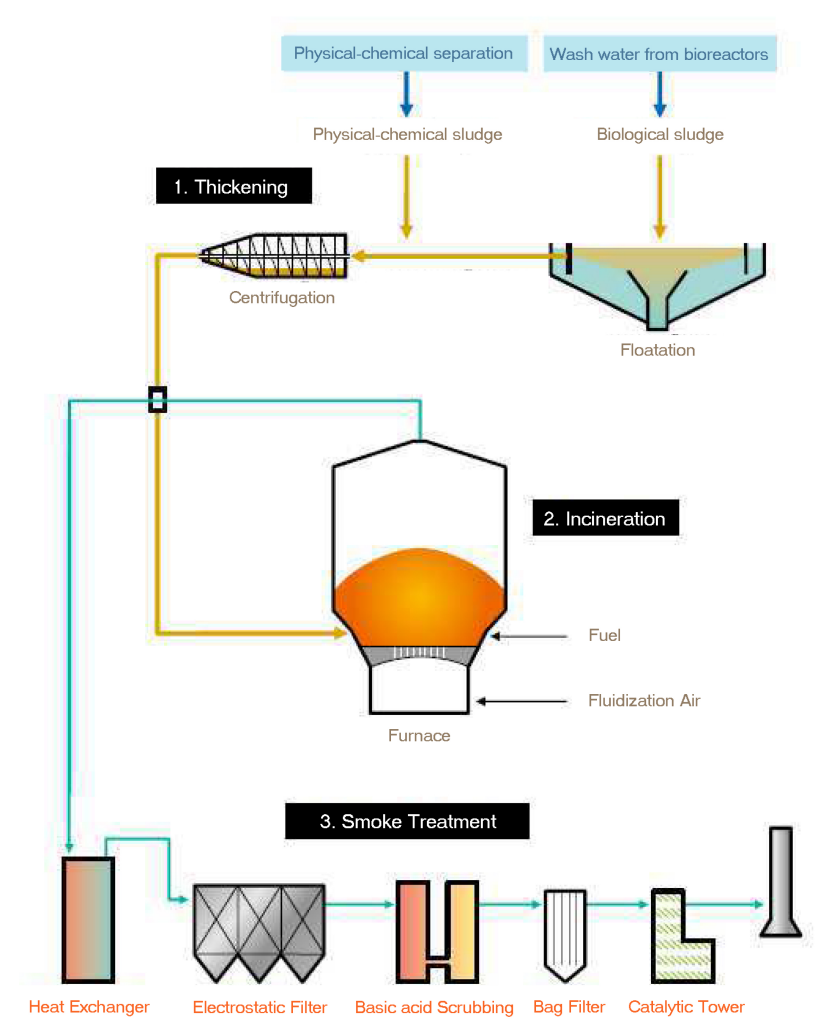

Figure 1. Sludge Treatment Diagrams.

stages. The preliminary treatment allows eliminate big particles like sand or fats. The second one, decantation, allows the elimination of much part of colloids, suspended solids and orthophosphates. The third and last one, biological treatment, allows the elimination of carbon and nitrogen pollution.

In Figure 1 we present sludge treatment part. Sludge is the result of WWT. First of all, sludge is treated passing by floatation and dehydration process in order to control the water concentration in the sludge, in a way that it does not disturb its incineration. In the first one air and polymer are injected to promote in the process of water and sludge separation and in the second one another polymer is injected to sludge thickening. Then, sludge is injected inside the fluidized-bed furnace to incineration. The smoke produced is then treated by five different processes, aimed to control smoke temperature and pollution level. Hot air issued of the smoke temperature treatment represent the fluidised air in order to maintain furnace temperature.

Relative data from the sludge treatment process of Seine Centre Plant is given by SIAAP for the development of this research.

\subsection{Incineration Process}

The incineration in the Waste Water Treatment Plants (WWTPs) is a thermal recycling relative to sewage sludge treatment. The purpose of this technologies is to solve hygiene problems while the WWTPs effluents are considered as a source of contamination (Mailler et al., 2014). Despite the complexity of the combustion mechanism involved and the strongly non-linearity, the use of this technology has increased thanks to new thermal recovery strategies (Martins et al., 2014; Tong et al., 2012; Ravelli et al., 2008; Khiari et al., 2008; Hadavand et al., 2008; Li and $\mathrm{Li}, 2016$ ).

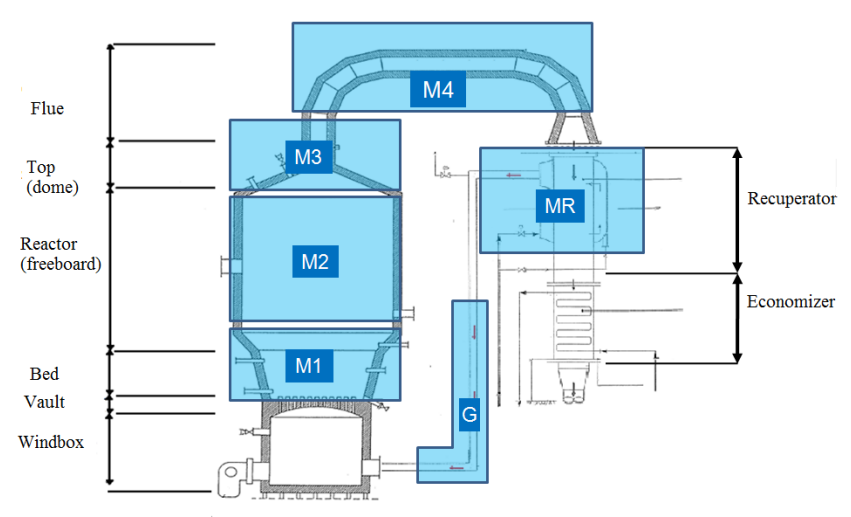

Figure 2. The incineration process sketch.

Figure 2 presents the considered incineration process which is composed by two principal process: the furnace (incinerator) and the heat Exchanger.

\subsubsection{The Furnace}

The Seine center furnace is called Pyrofluid incinerator. it is based on the bubbling fluidized bed technology. This system is consist of 6 important parts as shown in Figure 2:

- Windbox: it ensures the preheated fluidised air transfer to the Bed, and has a major role in the boot process.

- Vault: it ensures uniform distribution of air thanks to tuyeres.

- Fluidised bed: it is composed of sand as inert particles. The Injection fluidised air in the bed ensure uniform turbulence.

- Freeboard: its volume allows the complete combustion of organic material. In the reactor, the temperature should be maintained at $\mathbf{T} 2 \mathrm{~S}=850^{\circ} \mathrm{C}$ for at least 2 seconds.

- Dome: at this level, $\mathrm{NH}_{4} \mathrm{OH}$ is injected in order to reduce $N O_{x}$ toxicity and water to avoid high temperature.

- Flue: it ensures fume transport to the heat exchanger.

The load temperature of this process is from $800^{\circ} \mathrm{C}$ to $950^{\circ} \mathrm{C}$ and it ensures the total combustion of sludge in just few seconds. This technique reduces the volumes of the 
incinerated waste by $90 \%$ and the mass by $70 \%$ (Rabah et al., 2015).

\subsubsection{The Heat Exchanger}

In fact, the heat exchanger is composed by two exchangers blocks: recuperator and economizer.

In order to ensure an optimal energy recovery, the thermal energy resulting of combustion phenomenon is recycled in the process thanks to the recuperator that preheats the fluidizing air and the economizer, allows the water heater for other needs at the station.

\section{Identification Process Overview}

The fluidized bed incineration is one of the key innovative technologies in the field of sewage sludge incineration treatment but also the most complex one because of the difficulty of establishing a representative model of the process in order to improve the system efficiency. However, to understand the dynamics of fluidized bed is necessary but not sufficient to improve the performance of this technology. The development of numeric identification methods provide tools to model the dynamics of these complex systems. These models are usually used in order to improve control and guarantee optimal performance.

The furnace is driven by external excitation, these are the system "Inputs". The reaction of the process which is measured by the sensors is called system "Output". The objective in this step is to synthesize a mathematical model that describes the system reaction, this model will be able to predict the output of the system.

The incineration process is decomposed into 6 submodels interconnected between them as presented in Figure 3.

\subsection{Sludge Incineration sub-models: Input- output interaction.}

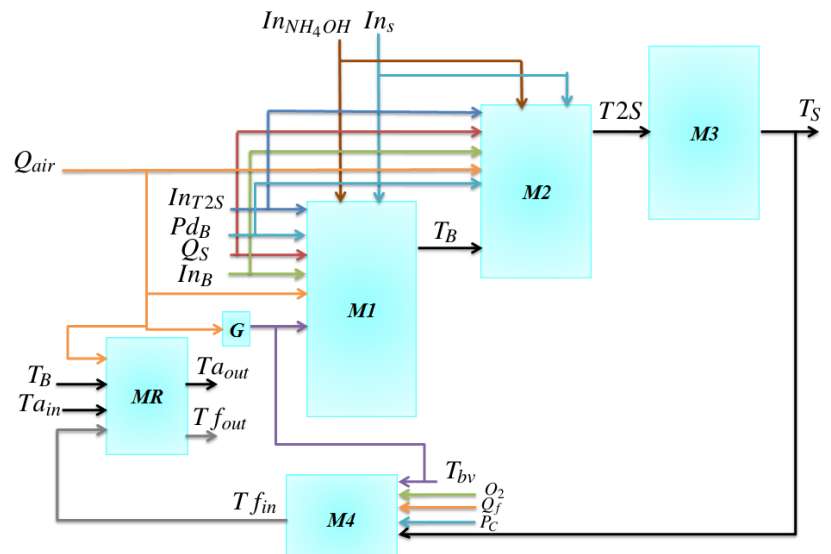

Figure 3. Sludge Incineration: input-output Sub-model.

- $M 1$ - Bed Model $\left(T_{B}\right)$.

- $M 2$ - Reactor Model (T2S).
- $M 3$ - Top Reactor Model $\left(T_{S}\right)$.

- M4 - Flue model $\left(T f_{\text {in }}\right)$.

- $M R$ - Recuperator Model $\left(T f_{\text {out }}, T a_{\text {in }}\right)$

- $G$ - Model of thermal dissipation $\left(T_{b v}\right)$

\subsection{Identification Strategy}

The identification is to find mathematical models of systems based on experimental data (black box model) and available knowledge (Grey box model or semi-physical model). These models must provide an approximation of the considered system in order to calculate the physical parameters or design simulation algorithms, monitoring or control. The classic approach is to formalize the available knowledge, to collect experimental data and estimate the structure, the parameters, and end up with validation. The identification methods are generally based on minimizing of the "prediction error". In other words, these techniques establish a model by reducing prediction error of the future output $Y_{i}$ while considering past output $Y_{0}$ and input $U_{0}$ and $U_{i}$. In this case, we present validation result of identification model based on the subspace state space system identification method (Favoreel et al., 2000; Hachicha et al., 2014; Jamaludin et al., 2013; Van Overschee and De Moor, 1994; Viberg, 1995). All models are presented as a linear discrete time invariant state space model (LTI) (Pekpe, 2004; Van Overschee and De Moor, 2012):

$$
\left\{\begin{array}{l}
x_{k+1}=A x_{k}+B u_{k}+v_{k} \\
y_{k}=C x_{k}+D u_{k}+\omega_{k}
\end{array}\right.
$$

Where $x_{k} \in \mathbb{R}^{n}$ is the state vector at discrete time instant $k, u_{k} \in \mathbb{R}^{m}$ is the input, $y_{k} \in \mathbb{R}^{l}$ is the output while $v_{k} \in \mathbb{R}^{n}$ and $\omega_{k} \in \mathbb{R}^{l}$ are additional unobserved signals sequences, $v_{k}$ is the measurement noise and $\omega_{k}$ the process noise. The identification result was presented in (Rabah et al., 2016).

\section{Validation Methods}

The validation of identified models uses the relative reference-model criteria that compares the residuals of the identified model to the ones of a simplistic and reference model. In order to know error greatness, the absolute criteria will also be used. According to (Hauduc, 2011), neither the relative error criteria nor the graphical methods are considered. In fact, the relative error criteria does not offer a relation between two models as the relative reference-model and the graphical methods don't state a numerical result of its method, which resulting in a qualitative method.

\subsection{Absolute Criteria}

In this paper, absolute criteria approach avoid error compensation. And there is an optimal cost value of zero in this approach. Error dimensions are given in the square of the measured temperature unit. 
The AME method, defined by (2), denotes the absolute maximum error. It is used to know the model's behaviours, but it does not describe the real process very well. The MSE method, defined by (3), emphasizes high errors but it does not have a reference, which is difficult to decide if its result is satisfactory or not. The MSDE method, defined by (4), is calculated based on two time steps. It denotes peak's timing errors.

$$
\begin{gathered}
\operatorname{AME}\left({ }^{\circ} \mathrm{C}\right)=\max \left(\left|O_{i}-P_{i}\right|\right) \\
\operatorname{MSE}\left({ }^{\circ} \mathrm{C}^{2}\right)=\frac{1}{n} \sum_{i=1}^{n}\left(O_{i}-P_{i}\right)^{2} \\
\operatorname{MSDE}\left({ }^{\circ} \mathrm{C}^{2}\right)=\frac{1}{n-1} \sum_{i=1}^{n}\left(\left(O_{i}-O_{i-1}\right)-\left(P_{i}-P_{i-1}\right)\right)^{2}
\end{gathered}
$$

\subsection{Relative reference-model criteria}

The NRMSE method, defined by (5), emphasizes larger errors in the identified model and can be compared to other methods to indicate the influence of this type of error. One could state that larger errors would not be emphasized by this method, but as seen in (5), the square root is present in both numerator and denominator. The denominator root underlines errors when the observed data is much closer to its mean than to predicted data.

The LCE method, defined by (6), emphasizes very low magnitude errors. Natural logarithm in both numerator and denominator puts all residuals in a lower scale in a way that smaller residuals have influences in results closer to the influence of greater ones. Then, greater errors continue to be considered in LCE criteria, but with lower emphasis.

Finally, NMSE method, defined by (7), also emphasizes high errors, but without a square root. It seems that greater residuals will give lower criteria values, but results of this criteria tends to be more elevated than NRMSE - i.e. better results - when the observed data is closer to its mean than to predicted data.

All these methods avoid errors compensations and have an optimal cost value of 1 . Values close to zero indicate that the identified model is not better than the reference model, which is all in this case a constant equal to observed data mean. Negative values indicate a model worse thfim ithe reference model. Lower possible value is negative

$$
\begin{gathered}
\operatorname{NRMSE}(\%)=1-\frac{\sqrt{\sum_{i=1}^{n}\left(O_{i}-P_{i}\right)^{2}}}{\sqrt{\sum_{i=1}^{n}\left(O_{i}-\bar{O}\right)^{2}}} \\
\operatorname{LCE}(\%)=1-\frac{\sum_{i=1}^{n}\left(\ln O_{i}-\ln P_{i}\right)^{2}}{\sum_{i=1}^{n}\left(\ln O_{i}-\overline{\ln O}\right)^{2}}
\end{gathered}
$$

$$
\operatorname{NMSE}(\%)=1-\frac{\sum_{i=1}^{n}\left(O_{i}-P_{i}\right)^{2}}{\sum_{i=1}^{n}\left(O_{i}-\bar{O}\right)^{2}}
$$

\section{Results and Discussions}

This section presents the validation of each sub model identified using a subspace method. The recuperator part that comes after the flue, is divided in two models. One analyses the fluidised air and the other deals with the fume temperature. The models are called $M R_{\text {AirOut }}$ and $M R_{\text {SmokeOut }}$, respectively. The output signal of each model is the temperature of its respectively furnace section. validation algorithms are developed using MATLAB interface in order to get NRMSE, NMSE, MSE, LCE, AME and MSDE results.

Tables 1 and 2 show results of each validation method for each sub model for absolute criteria and relative reference-model criteria, respectively. Two different furnace operation modes are presented: one with reactor fuel injection and the other without fuel injection.

Considering Section 4, absolute criteria has subjective results, having different quality standard values depending on very specific system characteristics. However, these methods could be useful for superficial analysis. It is seen in Table 1 that the models present tolerable AME results, except for the model $M R_{\text {SmokeOut }}$, knowing that temperature in the furnace can reach values in the order of $900^{\circ} \mathrm{C}$. MSE results cannot be analysed singly due to its subjectivity, but the results of the same model in both operation

\begin{tabular}{|c|c|c|c|c|}
\hline & Sub Model & $A M E$ & $M S E$ & $M S D E$ \\
\hline & MI & 4.40 & 2.70 & 0.07 \\
\hline & $M 2$ & 10.12 & 7.31 & 1.51 \\
\hline Without & M3 & 6.00 & 2.00 & 0.16 \\
\hline \multirow[t]{6}{*}{ Fuel } & M4 & 28.85 & 15.32 & 0.08 \\
\hline & $G$ & 6.43 & 8.74 & 0.05 \\
\hline & $M R_{\text {AirOut }}$ & 14.31 & 38.63 & 0.02 \\
\hline & $M R_{\text {SmokeOut }}$ & 12.59 & 25.65 & 0.05 \\
\hline & $M 1 / \mathrm{M} 2$ & 22.25 & 18.44 & 2.65 \\
\hline & $M 3$ & 33.19 & 53.08 & 0.52 \\
\hline With & M4 & 10.29 & 2.98 & 0.08 \\
\hline \multirow[t]{3}{*}{ Fuel } & G & 8.49 & 1.83 & 0.05 \\
\hline & $M R_{\text {AirOut }}$ & 21.50 & 16.12 & 0.05 \\
\hline & $M R_{\text {SmokeOut }}$ & 52.47 & 142.88 & 0.34 \\
\hline
\end{tabular}
modes can be compared. It is seen that M1, M2, M3 and $M R_{\text {Smoke } O u t}$ have better MSE values in operation without reactor fuel injection than operation with fuel.

Table 1. Absolute Criteria Results of Each Validation Method with and without Reactor Fuel Injection.

\subsection{Relative Reference-Model Criteria Results}

At first, we note that the values have a sorting relation, in a way that if all the NRMSE values are sorted in ascend- 
Table 2. Relative Reference-Model Results of Each Validation Method with and without Reactor Fuel Injection.

\begin{tabular}{ccccc}
\hline & Sub Model & NRMSE & LCE & NMSE \\
\hline \multirow{4}{*}{ Without } & M1 & 55.24 & 79.95 & 79.96 \\
Fuel & M3 & 53.20 & 78.07 & 78.09 \\
& M4 & 83.65 & 97.31 & 97.34 \\
& $G$ & 82.53 & 92.59 & 92.79 \\
& $M R_{\text {AirOut }}$ & 73.30 & 96.96 & 96.95 \\
& $M R_{\text {SmokeOut }}$ & 66.68 & 88.76 & 92.87 \\
With & $M 1 /$ M2 & 57.97 & 82.34 & 82.33 \\
Fuel & M3 & 48.29 & 73.62 & 73.26 \\
& M4 & 61.69 & 85.44 & 85.32 \\
& $G$ & 85.73 & 98.00 & 97.96 \\
& $M R_{\text {AirOut }}$ & 73.73 & 93.28 & 93.10 \\
& $M R_{\text {SmokeOut }}$ & 68.35 & 90.68 & 89.98 \\
\hline
\end{tabular}

ing or descending order, the other two criteria results will follow the same order. Thus, the bigger NRMSE values are, the bigger LCE or NMSE values will be. It does not imply a linear relation among these criteria. It just makes it clear the different emphasis that each method gives to residuals types.

Considering this point, it can also be said that all the models have similarities in the type of the error. For example, M1 with fuel has a NRMSE result of $42,01 \%$ and LCE result of $65,92 \%$ and M1 without fuel has a NRMSE result of 55,24\% and LCE result of 79,95\%.

Moreover, it can also be suggested that some data are correlated, as it has the same type of error. It means that the inputs and outputs signal of one sub model may be related to the inputs and outputs signal of another one.

Each system has different response curves, like swinging and noisy curves, slowly and soft curves, periodical curves and more. Like each validation method lay emphasis on a kind of residual, each system should adopt a different validation method. For this paper, fluidized-bed furnace system is identified and should be validated. As the temperature curves have so many peaks, peak timing validation methods like MSDE (Hauduc, 2011) should be chosen. Looking at the residuals values, it is noted that in most cases that their values are not so high. Thus, a validation method for low magnitude residuals may be adopted. It is shown in Table 2 that the LCE results for most of models are excellent.

As for on-line identification, validation methods need to be extremely secure in some cases. All the precautions must be taken to avoid inefficient or unstable models. To prevent this situation, redundancy methods should be performed. In a general view, a method that takes in account high and low magnitudes residuals could do well. As a suggestion, LCE and NRMSE methods should be adopted simultaneously. This on-line identified model validation has not yet been proven, but it is a subject of next studies.

\section{Conclusions}

This paper investigates model validation of a fluidizedbed incineration furnace by different quality criteria. The model of each part of the furnace is identified with the N4SID method using MATLAB function. The three methods adopted present good results. Regarding the type of error of the dynamic system being studied, low magnitude error methods should be performed. LCE method presents excellent results. For on-line model identification, both LCE and NRMSE are suggested.

\section{Notation}

\begin{tabular}{|c|c|}
\hline SIAAP & Paris urban area waste-water treatment authority. \\
\hline NRMSE & Normalized Root Mean Square Error. \\
\hline$L C E$ & Logarithmic residuals Comparison errors. \\
\hline NMSE & Normalized Mean Square Error. \\
\hline$A M E$ & Absolute Maximum Error. \\
\hline$M S E$ & Mean Square Error. \\
\hline$M S D E$ & Mean Square Derivative Error. \\
\hline$O_{i}$ & Observed model data. \\
\hline$P_{i}$ & Predicted model data. \\
\hline $\bar{O}$ & Observed data mean \\
\hline$n$ & The number of validation data. \\
\hline$T 2 S$ & Reactor Temperature (Temperature of $2 \mathrm{~s})\left({ }^{\circ} \mathrm{C}\right)$. \\
\hline$T_{S}$ & Temperature in the top of the incinerator $\left({ }^{\circ} \mathrm{C}\right)$. \\
\hline$T_{B}$ & Bed Temperature $\left({ }^{\circ} \mathrm{C}\right)$. \\
\hline$T_{b v}$ & Windbox Temperature $\left({ }^{\circ} \mathrm{C}\right)$. \\
\hline $\operatorname{In}_{T 2 S}$ & Reactor fuel injection $(l / s)$. \\
\hline $\operatorname{In}_{B}$ & Bed fuel injection $(l / s)$. \\
\hline$Q_{S}$ & Sludge flow $(l / s)$. \\
\hline $\mathrm{In}_{\mathrm{NH}_{4} \mathrm{OH}}$ & $\mathrm{NH}_{4} \mathrm{OH}$ injection $(l / s)$. \\
\hline$I n_{s}$ & Water top reactor injection $(l / s)$. \\
\hline$Q_{\text {air }}$ & Fluidizing air flow $\left(\mathrm{Nm}^{3}\right)$ \\
\hline$P d_{B}$ & Bed differential pressure (mbar) \\
\hline$T f_{\text {in }}$ & Recuperator input fume temperature $\left({ }^{\circ} \mathrm{C}\right)$. \\
\hline$T f_{\text {out }}$ & Recuperator output fume temperature $\left({ }^{\circ} \mathrm{C}\right)$. \\
\hline$T a_{i n}$ & Recuperator input Air temperature $\left({ }^{\circ} \mathrm{C}\right)$. \\
\hline$T a_{\text {out }}$ & Recuperator output Air temperature $\left({ }^{\circ} \mathrm{C}\right)$. \\
\hline $\mathrm{O}_{2}$ & Oxygen measure $(\%)$ \\
\hline$Q_{f}$ & Flue gas flow $\left(\mathrm{Nm}^{3}\right)$ \\
\hline$P_{C}$ & Flue pressure $\left(\mathrm{Nm}^{3}\right)$. \\
\hline
\end{tabular}

\section{Acknowledgment}

This study is being conducted as part of Axe 3 of the program MOCOPEE ${ }^{1}$ (phase 1. 2014 - 2017). The authors would like to thank MOCOPEE program for the financial support.

\section{References}

W. Favoreel, B. De Moor, and P. Van Overschee. Subspace state space system identification for industrial processes. Journal of process control, 10(2):149-155, 2000.

C. Grossmann, C. N. Jones, and M. Morari. System identification via nuclear norm regularization for simulated moving bed processes from incomplete data sets. In Decision and Control, 2009 held jointly with the 2009 28th Chinese Control Conference. CDC/CCC 2009. Proceedings of the 48th IEEE Conference on, pages 4692-4697. IEEE, 2009.

${ }^{1}$ MOCOPEE: MOdélisation, Contrôle et Optimisation des Procédés d'Epuration des Eaux: www.mocopee.com 
S. Hachicha, M. Kharrat, and A. Chaari. N4SID and MOESP algorithms to highlight the ill-conditioning into subspace identification. International Journal of Automation and Computing, 11(1):30-38, 2014. ISSN 1476-8186.

A. Hadavand, A. A. Jalali, and P. Famouri. An innovative bed temperature-oriented modeling and robust control of a circulating fluidized bed combustor. Chemical Engineering Journal, 140(1):497-508, 2008. doi:10.1016/j.cej.2007.11.032.

$\mathrm{H}$. Hauduc. Modeles biocinétiques de boues activées de type ASM: Analyse théorique et fonctionnelle, vers un jeu de parametres par défaut. $\mathrm{PhD}$ thesis, Laval University, 2011.

I. W. Jamaludin, N. A. Wahab, N. S. Khalid, S. Sahlan, Z. Ibrahim, and M.F. Rahmat. N4sid and moesp subspace identification methods. pages 140-145. IEEE, 2013. doi:10.1109/CSPA.2013.6530030.

B. Khiari, F. Marias, F. Zagrouba, and J. Vaxelaire. Transient mathematical modelling of a fluidized bed incinerator for sewage sludge. Journal of Cleaner Production, 16(2):178191, 2008. doi:10.1016/j.jclepro.2006.08.020.

J. Kojio, H. Ishibashi, R. Inoue, S. Ushida, and H. Oku. Mimo closed-loop subspace model identification and hovering control of a 6-dof coaxial miniature helicopter. In SICE Annual Conference (SICE), 2014 Proceedings of the IEEE, pages 1679-1684. IEEE, 2014.

S. Li and Y. Li. Model predictive control of an intensified continuous reactor using a neural network wiener model. Neurocomputing, 2016. doi:10.1016/j.neucom.2015.12.048.

R. Mailler, J. Gasperi, V. Rocher, S. Gilbert-Pawlik, D. GearaMatta, R. Moilleron, and G. Chebbo. Biofiltration vs conventional activated sludge plants: what about priority and emerging pollutants removal? Environmental Science and Pollution Research, 21(8):5379-5390, 2014.

M. A. F. Martins, A. C. Zanin, and D. Odloak. Robust model predictive control of an industrial partial combustion fluidized-bed catalytic cracking converter. Chemical Engineering Research and Design, 92(5):917-930, 2014. doi:10.1016/j.cherd.2013.08.005.

R. Panday, B. D. Woerner, J. C. Ludlow, L. J. Shadle, and E. J. Boyle. Linear system identification of a cold flow circulating fluidized bed. Proceedings of the Institution of Mechanical Engineers, Part E: Journal of Process Mechanical Engineering, 223(1):45-60, 2009.

K. M. Pekpe. Identification par les techniques des sous-espacesapplication au diagnostic. $\mathrm{PhD}$ thesis, Institut National Polytechnique de Lorraine-INPL, 2004.

S. Rabah, H. Coppier, M. Chadli, N. Zoghlami, and M. S. Naceur. Régulation multi-variable pour un incinérateur à lit fluidisé circulant: approche lmi. In Gèmes Journées Doctorales / Journées Nationales MACS, 2015.

S. Rabah, H. Coppier, M. Chadli, S. Azimi, V. Rocher, D. Escalon, N. Zoghlami, and M. S. Naceur. Multi-variable industrial processes identification: Case of bubbling fluidized bed sewage sludge incinerator. In Control and Automation (MED), 2016 24th Mediterranean Conference on, pages 803808. IEEE, 2016.
S. Ravelli, A. Perdichizzi, and G. Barigozzi. Description, applications and numerical modelling of bubbling fluidized bed combustion in waste-to-energy plants. Progress in Energy and Combustion Science, 34(2):224-253, 2008. doi:10.1016/j.pecs.2007.07.002.

H. Tong, X. Zhao, and G. Liang. Design and simulation of fuzzy decoupling for combustion process of circulating fluidized bed boiler. In Advances in Electronic Engineering, Сотmunication and Management Vol. 2, pages 137-143. Springer, 2012.

P. Van Overschee and B. De Moor. N4sid: Subspace algorithms for the identification of combined deterministic-stochastic systems. Automatica, 30(1):75-93, 1994.

P. Van Overschee and B. L. De Moor. Subspace identification for linear systems: Theory - Implementation - Applications. Springer Science \& Business Media, 2012.

M. Viberg. Subspace-based methods for the identification of linear time-invariant systems. Automatica, 31(12):1835-1851, 1995. 